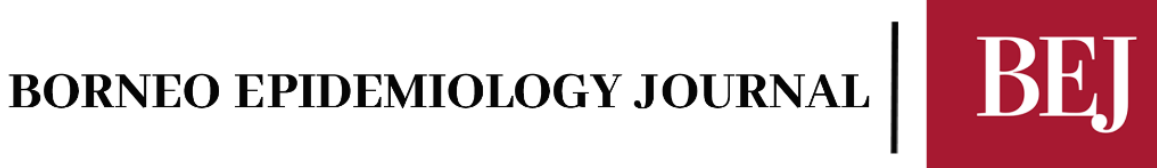

\section{Comparative Changes in Psychological Mindedness, Mindfulness, and Concordance Attitudes between Online and Face-to-Face Undergraduate Psychiatry Education in a University in Borneo, Malaysia}

Nicholas Tze Ping Pang ${ }^{1}$, Mohd Amiruddin Mohd Kassim¹*, Wendy Diana Shoesmith ${ }^{1}$, Sandi James ${ }^{2}$

\section{Abstract}

Introduction: Psychiatry posting is one of essential posting for medical students in Universiti Malaysia Sabah. Apart from learning about mental health disorder, students are also exposed to various psychotherapies techniques are crucial in psychiatric practise. However, in view of COVID-19, online learning had to be adopted, instead of the traditional face-to-face learning.

Methods: The study aimed to assess the difference in diverse psychological constructs, such as psychological mindedness, flexibility, and mindfulness; pre- \& post-psychiatry posting, and to determine whether online learning was comparable to face-to-face learning. The study was done on 58 undergraduate medical student populations, utilizing a set of scales to determine the psychological constructs, viz., balanced Index of psychological mindedness, Leeds attitudes to Concordance Scale II (LATCon II), the mindful attention awareness scale, and the acceptance and action questionnaire-II, which were administered before $\&$ after completion of the posting.

Results: Results were subsequently analysed using IBM SPSS. Interestingly, both control group (mean difference $=15.155, p=0.004$ ) and online psychiatry posting (mean difference $12.691, p=0.014)$ had higher mindfulness level when compared to face-to-face psychiatry posting. Despite the common perception that psychiatry posting raises awareness regarding mental health, it was found that there were no significant differences in psychological constructs pre- and post-psychiatry posting. Interestingly, the online psychiatry posting also found to be as effective as the face-to-face psychiatry posting.

Conclusion: This study highlighted the applicability of online learning in psychiatry, which could be crucial in maintaining continuity of learning during these uncertain times.

Keywords: Online learning, Psychiatry, Psychological mindedness, Psychological flexibility, Mindfulness.

\footnotetext{
*Correspondence Email: amiruddink@ums.edu.my

${ }^{1}$ Faculty of Medicine and Health Sciences, Universiti Malaysia Sabah, Jalan UMS, 88400 Sabah, Malaysia

${ }^{2}$ Department of Social Work and Social Policy, School of Science, Health and Engineering, La Trobe University, Melbourne Victoria 3000, Australia
}

Received: 22/01/2021

Accepted: 09/06/2021 


\section{Introduction}

Psychotherapy skills are crucial in the global mental health agenda of creating higher levels of mental health literacy, increasing access to crucial psychotherapy interventions, and improving the psychological wellbeing of the general public as a primary prevention initiative. Despite efforts by the United Kingdom in its Increasing Access to Psychological Therapies (IAPT) nationwide initiative, persistent shortfalls in clinical psychologist yields indicate that a more realistic approach is to task shift core psychotherapeutic skills to nonspecialist providers, including all junior doctors. Moreover, psychotherapy training is known to have positive effects on various psychological indices, including psychological mindedness (Boylan, M.B. et. al., 2006), mindfulness, and psychological flexibility. Psychological mindedness is defined as having interest into one's own psychological processes and the psychological processes of others (Farber, B.A. et. al., 1985). Mindfulness is defined as a state of being able to remain in the present moment and be non-judgemental to one's thoughts and feelings (Kabat, Z.J. et. al., 1993), and treating oneself with flexibility, openness to experience, curiosity, and kindness to oneself. Psychological flexibility on the other hand is defined as flexible psychological reactions in line with an individual's values, with the converse being psychological inflexibility, namely rigidity of psychological reactions in order to avoid distress, uncomfortable feelings and thoughts (Hayes, S.C. et. al., 2006). All these are psychological process variables that may be theoretically improved by a course of psychotherapy training.

At the same time, in training a new generation of medical professionals, it is increasingly crucial to instil values of collaborative practise from the onset. Collaborative practise refers to when "multiple healthcare workers from different professional backgrounds work together with families, patients, carers and communities to deliver the highest quality of care" (Gilbert, J.H. et. al., 2010). One important method of doing so is via a shared decision making (SDM) model. SDM encourages teams and patients to discuss reasonable healthcare options together, using the best available evidence, so patients are supported to construct informed preferences about available options (Charles, C. et. al., 1999). It is a major tenet of evidence-based medicine as one of the prerequisites is to incorporate patient's values and preferences, i.e. employing SDM (Montori, V.M. et. al., 2008).

In the medical curriculum of Universiti Malaysia Sabah, a comprehensive public university in Borneo, as part of the psychiatry posting of six weeks, medical students are given brief exposures to three types of psychotherapies, namely Motivational Interviewing, Acceptance and Commitment Therapy, and Cognitive Behavioural Therapy, both as a seminar and a roleplay form. Concurrently there is also a three-hour SDM tutorial provided in roleplay form. There have as yet been no efforts to adequately assess whether there is any efficacy in teaching such skills, and whether they lead to corresponding increases in relevant indices.

One other spanner in the works in recent months for the psychiatry posting has been the advent of COVID-19, which has necessitated transitioning of all educational activities to online teaching via video call applications. This pandemic has certainly caused huge implications in terms of mental health and social norms of students and public alike (Pang N.T.P. et. al., 2020; Kassim, M.A.M. et. al., 2020; Wan, M.Y.W.M.A. et. al., 2021; Dawson, D.L. et. al., 2020; Kumar, A. et. al., 2020; Lee, S.C. et. al., 2020; Grover, S. et. al., 2020; Zainudin, S.P. et. al., 2020; Rab, S. et. al., 2020 \& Cahapay, M.B. et. al., 2020), and has been responsible for increased prevalence of psychopathologies among university students 
(Kassim, M.A.M. et. al., 2020; Wathelet, M. et. al., 2020; Padrón, I. et. al., 2021; Liu, C.H. et. al., 2020; Marelli, S. et. al., 2021 \& Mudenda, S. et. al., 2020). Hence all psychotherapy and SDM training were transferred to online teaching for three postings spanning a total of six months. Hence, there is an imperative to assess whether online modalities yield the same benefits in terms of improvement of indices of psychological process variables and SDM skills. This is a crucial question to address, as if online skills training modules work with similar efficacy as face-to-face skills training modules, they can be used as suitable modalities to train larger numbers of people remotely.

Hence this study aims to assess a few things. Firstly, the study assesses whether exposure to the psychiatry posting would lead to increases in various constructs that reflect the following psychological processes: psychological mindedness, mindfulness, and psychological flexibility. Secondly, this study assesses the effectiveness of the posting in improving attitudes towards concordance, which represent a corollary measurement of student attitudes towards paternalism. Thirdly, this study aims to see if there are any differences between the face-to-face batches, the online batches, and a control group comprised of students who had not undergone the psychiatry posting.

\section{Methods}

Prior to the study commencement, the Medical Research Ethics Committee of Universiti Malaysia Sabah provided regulatory consent and vetting. Informed consents were obtained from all participants. The participants were recruited by applying convenience sampling in an undergraduate medical faculty in Borneo. Three groups of medical students were enrolled into this study. One group was the students who were in the six-week psychiatry posting which had been done all face-to-face (Group A1). The second group was the students who had undergone the entire six weeks posting through online classes (Group A2). The control group was a group of medical students who did not undergo the psychiatry posting as they were in the year below (Group C). There were 58 students participated

Students will be given explanations with regard the study, and only those students who provide informed consent will then proceed to sign informed consent sheets. Inclusion criteria were students who fell into the groups as above, gave informed consent, and did not have any acute medical or psychiatric issues.

At the baseline, all students will complete 5 questionnaires - a sociodemographic questionnaire, the Leeds Attitudes to Concordance Scale II (LATCon II) measuring attitudes towards paternalism and concordance, the Balanced Index of Psychological Mindedness, the Mindful Attention Awareness Scale, and the Acceptance and Action Questionnaire-II measuring psychological flexibility. For Group A1 and Group A2, measurements were performed at two separate time points - at T1: the beginning of their posting, and at T2: the end of their posting. For Group C, measurements for T1 and T2 were measured six weeks apart, to simulate the duration of time undergoing a psychiatry posting.

\section{Leeds Attitudes to Concordance Scale II (LATCon II)}

The LATCon II is a revised and more concise form of the previous Leeds Attitudes to Concordance Scale (LATCon), assessing practitioners' and patients' attitudes to concordance (Knapp, P. et. al., 2009). It has 20-item scale measured using a 4-point Likert scale: strongly disagree (0), disagree (i), agree (ii), and strongly agree (iii). It also includes five items (i.e. 
Items $11,14,15,18$, and 20) in the scale which were reversely scored. Higher scores on the LATCon II indicate a more positive attitude, while lower scores indicate a more negative attitude (Way, D. et. al., 2013). The scale has satisfactory psychometric properties with Cronbach's $\alpha$ of 0.82 , as well as good test-retest reliability (Pearson's correlation coefficient $=0.64)$.

\section{Balanced Index of Psychological Mindedness (BIPM)}

BIPM was developed in 2009 as a brief scale to measure the psychological mindedness level in individuals (Nykliček, I. et. al., 2009). It consists of 14 items and two factors, namely Interest and Insight. Items are rated on five-point Likert scale ranging from 0 (not true) to 4 (very much true), and a total score and two subscale scores (Interest and Insight) are calculated (Pang, N.T.P. et. al., 2020). Scores of the subscales can range from 0-28, with a higher score reflects a higher Interest, more Insight, and higher PM (Kassim, M.A.M. et. al., 2021). BIPM showed good psychometric properties, with Cronbach's $\alpha$ of 0.85 and 0.76 for Interest and Insight respectively, test-retest ( $\mathrm{r}=0.63$ for Interest; $\mathrm{r}=0.71$ for Insight), and concurrent validity ( $\mathrm{r}>0.40$ with related constructs).

\section{Mindful Attention Awareness Scale (MAAS)}

Mindful Attention Awareness Scale (MAAS) is designed to assess a core characteristic of mindfulness, namely, a receptive state of mind in which attention, informed by a sensitive awareness of what is occurring in the present, simply observes what is taking place (Brown, K.W. et. al., 2003). It has 15 items on a 6-point Likert scale ranging from 1 (almost always) to 6 (almost never). Higher scores reflect higher levels of dispositional mindfulness (Zainal, N.Z. et. al., 2015). It has Cronbach's $\alpha$ of 0.82 , with good CFA model data fits $(\chi 2(90, \mathrm{~N}=$ 327) 189.57 , GFI $=.92, \mathrm{CFI}=.91$, IFI $=.91$, PCFI $=.78$, and RMSEA $=.058$ ). It has been validated in medical students' population in Malaysia with Cronbach's $\alpha$ of 0.92 (Phang, C.K. et. al., 2016).

\section{Acceptance and Action Questionnaire-II (AAQ-II)}

Acceptance and action questionnaire (AAQ II) is an instrument to assess experiential avoidance and psychological inflexibility (Bond, F.W. et. al., 2011 \& Shari, N.I. et. al., 2019). It consists of 7 questions, rated on a 7-point Likert type scale from 1 (never true) to 7 (always true). Higher score on AAQ II indicates a greater level of experiential avoidance. AAQ-II has Cronbach's $\alpha$ of 0.88 , with the 3 - and 12-month test-retest reliability is 0.81 and 0.79 , respectively. It also demonstrated good model data fit on confirmatory factor analysis.

\section{Data Analysis}

SPSS IBM version 25.0 was employed for statistical analysis. Skewness and kurtosis were calculated for all study variables to assess normality. Subsequently, paired T-tests were performed to assess for significant pre- and post-changes for psychological mindedness, concordance, psychological flexibility, and mindfulness in all three groups. ANOVA was employed to assess the difference in scores between Groups A1, A2 and C, and to assess if there were any statistically significant variations between (T2-T1) between the three groups. Bivariate correlations were done using the relevant correlation coefficient between all study variables. Through hierarchical multiple regression too, the effect of the sociodemographic variables was calculated. 
Results

Table 1 shows the demographic variables of the participants. The majority of participants were students in face-to-face psychiatry posting group, female, Bumiputera Sabah in ethnicity, and of Islam religion. As per Table 2 and 3, the skewness and kurtosis for all items are well within the accepted limits of $+/-2$ suggesting they fall within the bounds of statistical normality. We also performed skewness and kurtosis for the three groups separately (pre-, post-, and control group), and all items fell within the bounds of statistical normality, even though each group had less than 30 participants. There was no significant difference seen in all scales between pre- and post-psychiatry posting in all groups as shown in Table 4. However, control group had the highest score for MAAS, followed by online Psychiatry posting, and face-to-face Psychiatry posting. The correlation of the treated data has been provided in Table $\mathbf{5}$.

Table 1: The respondents' background information $(n=58)$

\begin{tabular}{|c|c|c|c|}
\hline Background & Category & $\mathbf{N}$ & Percentage \\
\hline \multirow{3}{*}{$\begin{array}{l}\text { Students } \\
\text { Group }\end{array}$} & Face-to-face psychiatry posting group & 23 & 39.70 \\
\hline & Control Group & 16 & 27.60 \\
\hline & Online psychiatry posting group & 19 & 32.80 \\
\hline \multirow{2}{*}{ Gender } & Male & 12 & 20.70 \\
\hline & Female & 46 & 79.30 \\
\hline \multirow{8}{*}{ Ethnic } & Malay & 08 & 13.80 \\
\hline & Chinese & 10 & 17.20 \\
\hline & Indian & 10 & 17.20 \\
\hline & Bajau & 06 & 10.30 \\
\hline & Kadazan-Dusun & 08 & 13.80 \\
\hline & Murut & 01 & 01.70 \\
\hline & Bumiputera Sabah & 13 & 22.40 \\
\hline & Others & 02 & 03.40 \\
\hline \multirow{4}{*}{ Religion } & Islam & 25 & 43.10 \\
\hline & Christianity & 16 & 27.60 \\
\hline & Buddhism & 10 & 17.20 \\
\hline & Hinduism & 07 & 12.10 \\
\hline
\end{tabular}

Table 2: Descriptive statistics of pre-Psychiatry posting $(n=58)$

\begin{tabular}{lccccccc}
\hline Item & $\mathbf{N}$ & Minimum & Maximum & Mean & Standard Deviation & Skewness & Kurtosis \\
\hline BIPM & 58 & 19 & 49 & 36.09 & 06.817 & -0.185 & -0.510 \\
\hline MAAS & 58 & 28 & 89 & 61.12 & 15.317 & -0.019 & -0.684 \\
\hline AAQ-II & 58 & 07 & 49 & 22.71 & 09.852 & 0.418 & -0.111 \\
\hline LATCon-II & 58 & 33 & 60 & 45.14 & 05.995 & 0.346 & 0.160 \\
\hline
\end{tabular}

Table 3: Descriptive statistics of the post-Psychiatry posting $(n=58)$

\begin{tabular}{lccccccc}
\hline Item & $\mathbf{N}$ & Minimum & Maximum & Mean & Standard Deviation & Skewness & Kurtosis \\
\hline Item 1 & 58 & 25 & 50 & 36.26 & 06.217 & 0.261 & -0.499 \\
\hline Item 2 & 58 & 17 & 90 & 60.19 & 16.819 & -0.396 & -0.320 \\
\hline Item 3 & 58 & 07 & 49 & 22.10 & 09.711 & 0.381 & -0.284 \\
\hline Item 4 & 58 & 34 & 57 & 46.48 & 04.893 & -0.479 & -0.073 \\
\hline
\end{tabular}


Table 4: Statistical treatment of Group I \& J

\begin{tabular}{|c|c|c|c|c|c|c|c|}
\hline Item $^{\Delta}$ & Group 'I' & Group ' $J$ ' & $(\mathbf{I}-\mathbf{J})^{\#}$ & Standard Error & Significance & $\mathbf{L}^{\$}$ & $\mathbf{U}^{\$}$ \\
\hline \multirow{6}{*}{ BIPM } & \multirow{2}{*}{1} & 2 & -3.755 & 2.196 & 0.279 & -9.18 & 1.67 \\
\hline & & 3 & -0.551 & 2.091 & 1.000 & -5.72 & 4.61 \\
\hline & \multirow{2}{*}{2} & 1 & 3.755 & 2.196 & 0.279 & -1.67 & 9.18 \\
\hline & & 3 & 3.204 & 2.289 & 0.502 & -2.45 & 8.86 \\
\hline & \multirow[b]{2}{*}{3} & 1 & 0.551 & 2.091 & 1.000 & -4.61 & 5.72 \\
\hline & & 2 & -3.204 & 2.289 & 0.502 & -8.86 & 2.45 \\
\hline \multirow{6}{*}{ MAAS } & \multirow{2}{*}{1} & 2 & $-15.155^{*}$ & 4.534 & .004 & -26.35 & -3.96 \\
\hline & & 3 & $-12.691 *$ & 4.318 & .014 & -23.35 & -2.03 \\
\hline & \multirow{2}{*}{2} & 1 & $15.155^{*}$ & 4.534 & .004 & 3.96 & 26.35 \\
\hline & & 3 & 2.464 & 4.726 & 1.000 & -9.21 & 14.13 \\
\hline & \multirow{2}{*}{3} & 1 & $12.691 *$ & 4.318 & .014 & 2.03 & 23.35 \\
\hline & & 2 & -2.464 & 4.726 & 1.000 & -14.13 & 9.21 \\
\hline \multirow{6}{*}{ AAQ-II } & \multirow{2}{*}{1} & 2 & 3.690 & 3.223 & .771 & -4.27 & 11.65 \\
\hline & & 3 & 2.565 & 3.069 & 1.000 & -5.01 & 10.14 \\
\hline & \multirow{2}{*}{2} & 1 & -3.690 & 3.223 & .771 & -11.65 & 4.27 \\
\hline & & 3 & -1.125 & 3.359 & 1.000 & -9.42 & 7.17 \\
\hline & \multirow{2}{*}{3} & 1 & -2.565 & 3.069 & 1.000 & -10.14 & 5.01 \\
\hline & & 2 & 1.125 & 3.359 & 1.000 & -7.17 & 9.42 \\
\hline \multirow{6}{*}{$\begin{array}{l}\text { LAT } \\
\text { Con-II }\end{array}$} & \multirow{2}{*}{1} & 2 & -.177 & 1.949 & 1.000 & -4.99 & 4.64 \\
\hline & & 3 & -2.529 & 1.856 & .536 & -7.11 & 2.05 \\
\hline & \multirow{2}{*}{2} & 1 & .117 & 1.949 & 1.000 & -4.64 & 4.99 \\
\hline & & 3 & -2.352 & 2.032 & .756 & -7.37 & 2.66 \\
\hline & \multirow{2}{*}{3} & 1 & 2.529 & 1.856 & .536 & -2.05 & 7.11 \\
\hline & & 2 & 2.352 & 2.032 & .756 & -2.66 & 7.37 \\
\hline \multirow{6}{*}{$\begin{array}{l}\text { Post } \\
\text { BIPM }\end{array}$} & \multirow{2}{*}{1} & 2 & -4.383 & 1.972 & .091 & -9.25 & .49 \\
\hline & & 3 & -2.275 & 1.878 & .693 & -6.91 & 2.36 \\
\hline & \multirow{2}{*}{2} & 1 & 4.383 & 1.972 & .091 & -.49 & 9.25 \\
\hline & & 3 & 2.109 & 2.056 & .929 & -2.97 & 7.19 \\
\hline & \multirow{2}{*}{3} & 1 & 2.275 & 1.878 & .693 & -2.36 & 6.91 \\
\hline & & 2 & -2.109 & 2.056 & .929 & -7.19 & 2.97 \\
\hline \multirow{6}{*}{$\begin{array}{l}\text { Post } \\
\text { MAAS }\end{array}$} & 1 & 2 & $-19.302 *$ & 4.714 & .000 & -30.94 & -7.66 \\
\hline & 1 & 3 & $-17.108 *$ & 4.489 & .001 & -28.19 & -6.02 \\
\hline & 2 & 1 & $19.302 *$ & 4.714 & .000 & 7.66 & 30.94 \\
\hline & 2 & 3 & 2.194 & 4.913 & 1.000 & -9.94 & 14.33 \\
\hline & & 1 & $17.108^{*}$ & 4.489 & .001 & 6.02 & 28.19 \\
\hline & 3 & 2 & -2.194 & 4.913 & 1.000 & -14.33 & 9.94 \\
\hline & 1 & 2 & .402 & 3.213 & 1.000 & -7.53 & 8.34 \\
\hline & 1 & 3 & 1.336 & 3.059 & 1.000 & -6.22 & 8.89 \\
\hline Post & 0 & 1 & -.402 & 3.213 & 1.000 & -8.34 & 7.53 \\
\hline AAQ-II & 2 & 3 & .934 & 3.348 & 1.000 & -7.33 & 9.20 \\
\hline & & 1 & -1.336 & 3.059 & 1.000 & -8.89 & 6.22 \\
\hline & 3 & 2 & -.934 & 3.348 & 1.000 & -9.20 & 7.33 \\
\hline & 1 & 2 & .804 & 1.599 & 1.000 & -3.15 & 4.75 \\
\hline & 1 & 3 & -1.222 & 1.523 & 1.000 & -4.98 & 2.54 \\
\hline POSt & 2 & 1 & -.804 & 1.599 & 1.000 & -4.75 & 3.15 \\
\hline & 2 & 3 & -2.026 & 1.667 & .688 & -6.14 & 2.09 \\
\hline con-11 & & 1 & 1.222 & 1.523 & 1.000 & -2.54 & 4.98 \\
\hline & 3 & 2 & 2.026 & 1.667 & .688 & -2.09 & 6.14 \\
\hline
\end{tabular}

$\Delta$, Item: Dependent Variable; \#, I-J: Mean Difference; *I-J denoted with significant at the 0.05 level; \$ Lower Bound (L) \& Upper Bound (U) @ 95\% Confidence Interval; Legends: 1: Face-toface psychiatry posting $(\mathrm{N}=23)$; 2: Control group $(\mathrm{N}=16)$; 3: Online psychiatry posting $(\mathrm{N}=19)$; 
BEJ, VOLUME 2, ISSUE 1, JUNE 2021

Table 5: Correlation of the statistical treated data

\begin{tabular}{|c|c|c|c|c|c|c|c|c|c|}
\hline Item & Treatment & BIPM & MAAS & AAQ-II & $\begin{array}{l}\text { LAT } \\
\text { ConII }\end{array}$ & $\begin{array}{l}\text { Post } \\
\text { BIPM }\end{array}$ & $\begin{array}{c}\text { Post } \\
\text { MAAS }\end{array}$ & $\begin{array}{c}\text { Post } \\
\text { AAQ-II }\end{array}$ & $\begin{array}{c}\text { Post } \\
\text { LATConII }\end{array}$ \\
\hline \multirow{3}{*}{ BIPM } & $\begin{array}{c}\text { Pearson } \\
\text { Correlation }\end{array}$ & 1 & $0.430 * *$ & $-0.440 * *$ & 0.140 & $0.582 * *$ & $0.443 * *$ & $-0.390 * *$ & -0.107 \\
\hline & Sig. (2-tailed) & & 0.001 & 0.001 & 0.296 & 0.000 & 0.001 & 0.002 & 0.424 \\
\hline & $\mathrm{N}$ & 58 & 58 & 58 & 58 & 58 & 58 & 58 & 58 \\
\hline \multirow{3}{*}{ MAAS } & $\begin{array}{c}\text { Pearson } \\
\text { Correlation }\end{array}$ & $0.430 * *$ & 1 & $-0.696 * *$ & 0.082 & $0.325^{*}$ & $0.828 * *$ & $-0.513 * *$ & 0.092 \\
\hline & Sig. (2-tailed) & 0.001 & & 0.000 & 0.541 & 0.013 & 0.000 & 0.000 & 0.494 \\
\hline & $\mathrm{N}$ & 58 & 58 & 58 & 58 & 58 & 58 & 58 & 58 \\
\hline \multirow{3}{*}{ AAQ-II - } & $\begin{array}{c}\text { Pearson } \\
\text { Correlation }\end{array}$ & $-0.440 * *$ & $-0.696 * *$ & 1 & -0.013 & $-0.294 *$ & $-0.611 * *$ & $0.705 * *$ & -0.053 \\
\hline & Sig. (2-tailed) & 0.001 & 0.000 & & 0.923 & 0.025 & 0.000 & 0.000 & 0.6 .90 \\
\hline & $\mathrm{N}$ & 58 & 58 & 58 & 58 & 58 & 58 & 58 & 58 \\
\hline \multirow{3}{*}{$\begin{array}{l}\text { LAT } \\
\text { ConII }\end{array}$} & $\begin{array}{c}\text { Pearson } \\
\text { Correlation }\end{array}$ & 0.140 & 0.082 & -.013 & 1 & $0.259 *$ & 0.076 & -0.020 & $0.299 *$ \\
\hline & Sig. (2-tailed) & 0.296 & 0.541 & 0.923 & & 0.049 & 0.571 & 0.879 & 0.023 \\
\hline & $\mathrm{N}$ & 58 & 58 & 58 & 58 & 58 & 58 & 58 & 58 \\
\hline \multirow{3}{*}{$\begin{array}{l}\text { Post- } \\
\text { BIPM }\end{array}$} & $\begin{array}{c}\text { Pearson } \\
\text { Correlation }\end{array}$ & $0.582 * *$ & $0.325^{*}$ & $-0.294 *$ & $0.259 *$ & 1 & $0.357 * *$ & $-0.417 * *$ & 0.59 \\
\hline & Sig. (2-tailed) & 0.000 & 0.013 & 0.025 & 0.049 & & 0.006 & 0.001 & 0.649 \\
\hline & $\mathrm{N}$ & 58 & 58 & 58 & 58 & 58 & 58 & 58 & 58 \\
\hline \multirow{3}{*}{$\begin{array}{l}\text { Post - } \\
\text { MAAS }\end{array}$} & $\begin{array}{c}\text { Pearson } \\
\text { Correlation }\end{array}$ & $0.443 * *$ & $0.828 * *$ & $-0.611 * *$ & 0.076 & $0.357 * *$ & 1 & $-0.577 * *$ & 0.070 \\
\hline & Sig. (2-tailed) & 0.001 & 0.000 & 0.000 & 0.571 & 0.006 & & 0.000 & 0.600 \\
\hline & $\mathrm{N}$ & 58 & 58 & 58 & 58 & 58 & 58 & 58 & 58 \\
\hline \multirow{3}{*}{$\begin{array}{c}\text { Post- } \\
\text { AAQ-II }\end{array}$} & $\begin{array}{c}\text { Pearson } \\
\text { Correlation }\end{array}$ & $-.390 * *$ & $-.513 * *$ & $.705 * *$ & -0.020 & $0-.417 * *$ & $-0.577 * *$ & 1 & -0.237 \\
\hline & Sig. (2-tailed) & 0.002 & 0.000 & 0.000 & 0.879 & 0.001 & 0.000 & & 0.074 \\
\hline & $\mathrm{N}$ & 58 & 58 & 58 & 58 & 58 & 58 & 58 & 58 \\
\hline \multirow{3}{*}{$\begin{array}{l}\text { Post- } \\
\text { LAT } \\
\text { ConII }\end{array}$} & $\begin{array}{c}\text { Pearson } \\
\text { Correlation }\end{array}$ & -0.107 & 0.092 & -0.053 & $0.299 *$ & 0.059 & 0.070 & -0.237 & 1 \\
\hline & Sig. (2-tailed) & 0.424 & 0.494 & 0.690 & 0.023 & 0.659 & 0.600 & 0.074 & \\
\hline & $\mathrm{N}$ & 58 & 58 & 58 & 58 & 58 & 58 & 58 & 58 \\
\hline
\end{tabular}

\section{Discussion}

The key findings are that there is no difference before and after the posting in terms of mindfulness, psychological mindedness, psychological flexibility, and concordance. This finding is true for both online and face-to-face intervention groups. This may be due to multiple reasons. Firstly, the levels pre-posting may have already been sufficiently high, hence the ability of skills training and education to create significantly different changes in these markers may have been attenuated somewhat. Moreover, postings may be too short in terms of psychotherapy education compared to a full skills training course that lasts typically days, or a full session of psychotherapy as a client that can happen weekly and last months. 
Otherwise there are significant differences between mindfulness for the three groups, both pre- and post-posting. The highest mindfulness was experienced in the control group, followed by the online posting group, and surprisingly the face-to-face group had the lowest levels of mindfulness pre- and post-posting. There are multiple possibilities that can explain this finding. The MAAS employed measures more of state, rather than trait, mindfulness (Kotzé, M. et. al., 2016 \& Brown, K.W. et. al., 2007). The control and online groups both experienced clinical education from their home, whereas the face-to-face group had to attend all clinical sessions in hospitals, and subsequently had to face the potential feelings of judgement of being observed face-to-face by teachers and fellow medical students. Also, due to the more hectic nature of a face-to-face posting, there is potentially less opportunity to perform mindfulness activities and to be more mindful in their daily lives, as opposed to the online and control groups, who were able to demonstrate more state mindfulness. Psychological mindedness and psychological flexibility, on the other hand, may be more stable constructs that do not differ as much amongst individuals in different situations, and may require more time to be malleable (Bond, F.W. et. al., 2003; Bond, F.W. et. al., 2013; Lloyd, J., et. al., 2013 \& McCallum, M. et. al., 2003).

One of the somewhat interesting findings also is that there is no statistical difference between the online and face-to-face posting in terms of outcomes in terms of mindfulness, psychological mindedness, psychological flexibility, and concordance. This is important as it suggests that online modalities of skills development may not be as crippling as perceived. This corresponds to numerous studies that suggested that online learning is as effective as traditional face-to-face learning (Anggrawan, A. et. al., 2018; Neuhauser, C. et. al., 2002 \& Kalpokaite, N. et. al., 2020). Current literatures also suggested that learning medicine through online learning have big potential and shown encouraging impacts, especially in these challenging COVID-19 period (Torda A. et. al., 2020; Khalil, R. et. al., 2020; Agarwal, S. et. al., 2020; Rajab, M.H. et. al., 2020; Kassim, M.A.M. et. al., 2020). Using the breakout room functions of online teleconferencing applications, small group training and roleplay sessions can be simulated the same way as in face-to-face. Preliminary evidence from end of psychiatry posting examinations that have been undertaken by the online psychiatry postings also suggests that their examination results are similar to face-to-face postings. Though there is certainly no substitute to a face-to-face clinical education especially for surgical or handson rotations, for psychiatry training there is certainly no obstacle to using online methods.

The limitations of this study are certainly the small sample size per individual group, as the number of respondents in the online group is limited by the number of students who were required to undergo an online posting due to the COVID-19 lockdown. Hence, it was decided to match the control group numbers correspondingly. Otherwise, this study is limited due to the length of the psychiatry posting and the number of psychotherapy and SDM classes offered. However, this is beyond the researchers' control as it is related to the core learning outcomes.

\section{Conclusion}

In conclusion, it appears that psychiatry education can be done as efficaciously online as it can be done face-to-face. There is difference in levels of state mindfulness between online and face-to-face groups, which may actually suggest differences in circumstances surrounding rather than actual variations in level of mindfulness abilities. Psychotherapy is a crucial skill to be taught to budding doctors, as there is plenty of psychological distress out in the open, and it is crucial that we perhaps increase the provision of psychotherapeutic skill 
training in the medical education system in order to further increase levels of psychological mindedness, psychological flexibility, state mindfulness, and attitudes towards concordance in the doctors of tomorrow.

\section{Informed Consent}

All procedures followed were in accordance with the ethical standards of the responsible committee on human experimentation (institutional and national) and with the Helsinki Declaration of 1975, as revised in 2000 (5). Informed consent was obtained from all patients for being included in the study.

\section{Conflicts of Interest}

NTPP, WDS and SJ were lecturers in psychiatry in the medical faculty. MAMK declares no conflict of interest. No funding was received for this study.

\section{Ethical Approval}

Ethical approval was obtained from the Universiti Malaysia Sabah Medical Research Ethics Committee prior to commencement of this project. All participants provided informed consent.

\section{References}

Agarwal, S., Kaushik, J.S. (2020). Student's Perception of Online Learning during COVID Pandemic. Indian J Pediatr., 87(7), 554(1-1). https://doi.org/10.1007/s12098-020-03327-7

Anggrawan, A., Jihadil, Q.S. (2018). Comparative Analysis of Online E-Learning and Face-to-Face Learning: An Experimental Study. In: Proceedings of the 3rd International Conference on Informatics and Computing (ICIC), 8780495(1-4). https://doi.org/10.1109/IAC.2018.8780495

Bond, F.W., Bunce, D. (2003). The Role of Acceptance and Job Control in Mental Health, Job Satisfaction, and Work Performance. J. Appl. Psychol., 88(6), 1057-1067. https://doi.org/10.1037/0021-9010.88.6.1057

Bond, F.W., Hayes, S.C., Baer, R.A., Carpenter, K.M., Guenole, N., Orcutt, H.K., Waltz, T., Zettle, R.D. (2011). Preliminary Psychometric Properties of the Acceptance and Action Questionnaire-II: A Revised Measure of Psychological Inflexibility and Experiential Avoidance. Behav Ther., 42(4), 676-688. https://doi.org/10.1016/j.beth.2011.03.007

Bond, F.W., Lloyd, J., Guenole, N. (2013). The Work-Related Acceptance and Action Questionnaire: Initial Psychometric Findings and Their Implications for Measuring Psychological Flexibility in Specific Contexts. J. Occup. Organ. Psychol., 86(3), 331-347. https://doi.org/10.1111/joop.12001

Boylan, M.B. (2006). Psychological Mindedness as a Predictor of Treatment Outcome with Depressed Adolescents, Doctoral Dissertation, University of Pittsburgh, Diss. Abstr. Int. Sect. B. Sci. Eng., 1-132. http://d-scholarship.pitt.edu/id/eprint/6812

Brown, K.W., Ryan, R.M. (2003). The Benefits of Being Present: Mindfulness and Its Role in Psychological Well-Being. J. Pers. Soc. Psychol., 84(4), 822-848. https://doi.org/10.1037/0022$\underline{3514.84 .4 .822}$

Brown, K.W., Ryan, R.M., Creswell, J.D. (2007). Mindfulness: Theoretical foundations and evidence for its salutary effects. Psychol Inq., 18(4), 211-237. https://doi.org/10.1080/10478400701598298

Cahapay, M.B. (2020). Rethinking Education in the New Normal Post-COVID-19 Era: A Curriculum Studies Perspective. Aquademia, 4(2), ep20018(1-5). https://doi.org/10.29333/aquademia/8315 
Charles, C., Gafni, A., Whelan, T. (1999). Decision-Making in the Physician-Patient Encounter: Revisiting the Shared Treatment Decision-Making Model. Soc. Sci. Med., 49(5), 651-661. https://doi.org/10.1016/s0277-9536(99)00145-8

Dawson, D.L., Golijani, M.N. (2020). COVID-19: Psychological Flexibility, Coping, Mental Health, and Wellbeing in the UK during the Pandemic. J. Contextual Behav. Sci., 17, 126-134. https://doi.org/10.1016/j.jcbs.2020.07.010

Farber, B.A. (1985). The Genesis, Development, and Implications of Psychological-Mindedness in Psychotherapists. Psychotherapy: Theory, Research, Practice, Training, 22(2), 170-177. https://doi.org/10.1037/h0085490

Gilbert, J.H., Yan, J., Hoffman, S.J. (2010). A WHO Report: Framework for Action on Interprofessional Education and Collaborative Practice. J. Allied Health., 39(S1), 196-197. https://pubmed.ncbi.nlm.nih.gov/21174039/

Grover, S., Sahoo, S., Mehra, A., Avasthi, A., Tripathi, A., Subramanyan, A., Pattojoshi, A., Rao, G.P., Saha, G., Mishra, K.K., Chakraborty, K., Rao, N,P,, Vaishnav, M., Singh, O.P., Dalal, P.K., Chadda, R.K., Gupta, R., Gautam, S., Sarkar, S., Sathyanarayana, R.T.S., Kumar, V., Janardran, R.Y.C. (2020). Psychological impact of COVID-19 lockdown: An online survey from India. Indian J. Psychiatry, 62(4), 354-362. https://doi.org/10.4103/psychiatry.indianjpsychiatry_427_20

Hayes, S.C., Luoma, J.B., Bond, F.W., Masuda, A., Lillis, J. (2006). Acceptance and Commitment Therapy: Model, Processes and Outcomes. Behav. Res. Ther., 44(1), 1-25. https://doi.org/10.1016/j.brat.2005.06.006

Kabat, Z.J. (1993). Mindfulness Meditation: Health Benefits of an Ancient Buddhist Practice. In: Goleman, D., Garin, J., Eds., Mind/ Body Medicine, Consumer Reports, Yonkers, New York, 257-276. ISBN 13: 9780890435809

Kalpokaite, N., Radivojevic, I. (2020). Teaching Qualitative Data Analysis Software Online: A Comparison of Face-to-Face and E-Learning ATLAS.ti Courses. Int. J. Res. Method Educ., 43(3), 296-310. https://doi.org/10.1080/1743727X.2019.1687666

Kassim, M.A.M., Ayu, F., Kamu, A., Pang, N.T.P., Mun H.C., Algristian, H., Sahri, M., Hambali, N.L., Oma, A. (2020). Indonesian Version of the Fear of COVID-19 Scale: Validity and Reliability, Borneo. Epidemiol. J., 1(2), 124-135. https://jurcon.ums.edu.my/ojums/index.php/bej/article/view/2755/1805

Kassim, M.A.M., Pang, N., James, S. (2020). COVID-19 Pandemic - A Review and Assessing Higher Education Institution Undergraduate Student's Mental Health. Borneo Epidemiol. J., 1(2), 96-103. https://jurcon.ums.edu.my/ojums/index.php/bej/article/view/2746

Kassim, M.A.M., Pang, N.T.P., Mohamed, N.H., Kamu, A., Ho, C.M., Ayu, F., Rahim, S.S.S.A., Omar, A., Jeffree, M.S. (2020). Relationship between Fear of COVID-19, Psychopathology and Sociodemographic Variables in Malaysian Population. Int. J. Ment. Health Addict., 7, 1-8. https://doi.org/10.1007/s11469-020-00444-4

Kassim, M.A.M., Pang, N.T.P., Shoesmith, W.D., Tseu, M.W.L., Malindoi, E.A., Yeoh, Y.X., (2021). Validation of Bahasa Malaysia Version of Psychological Mindedness in a University Population. IIUM Med. J. Malaysia, 20(2), 81-88. https://doi.org/10.31436/imjm.v20i2.1718

Khalil, R., Mansour, A.E., Fadda, W.A., Almisnid, K., Aldamegh, M., Al-Nafeesah, A,, Alkhalifah, A., Al-Wutayd, O. (2020). The Sudden Transition to Synchronized Online Learning during the COVID-19 Pandemic in Saudi Arabia: A Qualitative Study Exploring Medical Students' Perspectives. BMC Med Educ. 20(1), 285(-10). https://doi.org/10.1186/s12909-020-02208-z

Knapp, P., Raynor, D.K., Thistlethwaite, J.E., Jones, M.B. (2009). A Questionnaire to Measure Health Practitioners' Attitudes to Partnership in Medicine Taking: LATCon II. Health Expect. 12(2), 175186. https://doi.org/10.1111/j.1369-7625.2009.00545.x

Kotzé, M., Nel, P. (2016). The psychometric properties of the Mindful Attention Awareness Scale (MAAS) and Freiburg Mindfulness Inventory (FMI) as measures of mindfulness and their relationship with burnout and work engagement. SA J Ind Psychol., 42(1), a1366(1-11). https://doi.org/10.4102/SAJIP.V42I1.1366 
Kumar, A., Nayar, K.R. (2020). COVID 19 and its mental health consequences. J. Ment. Health., 30(1), 1-2. https://doi.org/10.1080/09638237.2020.1757052

Lee, S.C., Ng, C.K., Mohd, K.M.A, Pang. N.T.P. (2020) Unique Challenges for Mental Health in Inpatient Settings Amid the COVID-19 Pandemic: Perspective from Sabah., Borneo. Epidemiol. J., 1(1), 79-87. https://jurcon.ums.edu.my/ojums/index.php/bej/article/view/2439/1606

Liu, C.H., Zhang, E., Wong, G.T.F., Hyun, S., Hahm, H.C. (2020). Factors Associated with Depression, Anxiety, and PTSD Symptomatology during the COVID-19 Pandemic: Clinical Implications for U.S. Young Adult Mental Health. Psychiatry Res. 290, 113172(1-7). https://doi.org/10.1016/j.psychres.2020.113172

Lloyd, J., Bond, F.W., Flaxman, P.E. (2013). The Value of Psychological Flexibility: Examining Psychological Mechanisms Underpinning a Cognitive Behavioural Therapy Intervention for Burnout. Work Stress, 27(2), 181-199. https://doi.org/10.1080/02678373.2013.782157

Marelli, S., Castelnuovo, A., Somma, A., Castronovo, V., Mombelli, S., Bottoni, D., Leitner, C., Fossati, A., Ferini, S.L. (2021). Impact of COVID-19 lockdown on sleep quality in university students and administration staff. J Neurol., 268(1), 8-15. https://doi.org/10.1007/s00415-020$\underline{10056-6}$

McCallum, M., Piper, W.E., Ogrodniczuk, J.S., Joyce, A.S. (2003). Relationships among Psychological Mindedness, Alexithymia and Outcome in Four Forms of Short-Term Psychotherapy. Psychol Psychother., 76(2), 133-144.

https://doi.org/10.1348/147608303765951177

Montori, V.M., Guyatt, G.H. (2008). Progress in Evidence-Based Medicine. JAMA, 300(15), 18141816. https://jamanetwork.com/journals/jama/fullarticle/182722

Mudenda, S., Zulu, A., Phiri, M.N., Ngazimbi, M., Mufwambi, W., Kasanga, M., Banda. M. (2020). Impact of Coronavirus Disease 2019 (COVID-19) on College and University Students: A Global Health and Education Problem. Aquademia, 4(2), ep20026 (1-2).

https://doi.org/10.29333/aquademia/8494

Neuhauser, C. (2002). Learning Style and Effectiveness of Online and Face-to-Face Instruction, Am. J. Distance Educ., 16(2), 99-113. https://doi.org/10.1207/S15389286AJDE1602_4

Nykliček, I., Denollet, J. (2009). Development and Evaluation of the Balanced Index of Psychological Mindedness (BIPM). Psychol. Assess., 21(1), 32-44. https://doi.org/10.1037/a0014418

Padrón, I., Fraga, I., Vieitez, L., Montes, C., Romero, E. (2021). A Study on the Psychological Wound of COVID-19 in University Students. Front Psychol., 12, 589927(1-15). https://doi.org/10.3389/fpsyg.2021.589927

Pang, N.T.P., Kamu, A., Hambali, N.L.B., Mun, H.C., Kassim, M.A. Mohamed NH, Ayu F, Rahim SSSA, Omar A, Jeffree MS. (2020). Malay Version of the Fear of COVID-19 Scale: Validity and Reliability. Int. J. Ment. Health Addict. 1-10. https://doi.org/10.1007/s11469-020-00355-4

Pang, N.T.P., Masiran, R., Tan, K.A., Kassim, A. (2020). Psychological Mindedness as a Mediator in the Relationship between Dysfunctional Coping Styles and Depressive Symptoms in Caregivers of Children with Autism Spectrum Disorder. Perspect Psychiatr Care., 56(3), 649-656. https://doi.org/10.1111/ppc.12481

Phang, C.K., Mukhtar, F., Ibrahim, N., Sidik M.S. (2016). Mindful Attention Awareness Scale (MAAS): Factorial Validity and Psychometric Properties in a Sample of Medical Students in Malaysia. J. Ment. Heal. Training, Educ. Pract., 11(5), 305-316. https://doi.org/10.1108/JMHTEP-02-2015-0011

Rab, S., Javaid, M., Haleem, A., Vaishya, R. (2020). Face Masks are New Normal after COVID-19 Pandemic. Diabetes Metab Syndr., 14(6), 1617-1619. https://doi.org/10.1016/j.dsx.2020.08.021

Rajab, M.H., Gazal, A.M., Alkattan, K. (2020). Challenges to Online Medical Education During the COVID-19 Pandemic. Cureus.12(7), e8966(1-8). https://doi.org/10.7759/cureus.8966

Shari, N.I., Zainal, N.Z., Guan, N.C., Sabki, Z.A., Yahaya, N.A. (2019). Psychometric Properties of the Acceptance and Action Questionnaire (AAQ II) Malay Version in Cancer Patients. PLOS ONE, 14(2), e0212788(1-12). https://doi.org/10.1371/journal.pone.0212788 
Torda A. (2020). How COVID-19 has Pushed Us into A Medical Education Revolution. Intern. Med. J., 50(9):1150-1153. https://doi.org/10.1111/imj.14882

Wan, M.Y.W.M.A., Badri, S.K.Z., Panatik, S.A., Mukhtar, F. (2021). The Unprecedented Movement Control Order (Lockdown) and Factors Associated With the Negative Emotional Symptoms, Happiness, and Work-Life Balance of Malaysian University Students During the Coronavirus Disease (COVID-19) Pandemic. Front. Psychiatry. 11, 566221(1-15). https://doi.org/10.3389/fpsyt.2020.566221

Wathelet, M., Duhem, S., Vaiva, G., Baubet, T., Habran, E., Veerapa, E., Debien, C., Molenda, S., Horn, M., Grandgenèvre, P., Notredame, C.E., D'Hondt, F. (2020). Factors Associated With Mental Health Disorders Among University Students in France Confined During the COVID-19 Pandemic. JAMA Netw Open, 3(10), e2025591(1-13). https://doi.org/10.1001/jamanetworkopen.2020.25591

Way, D. (2013). Critical Synthesis Package: Leeds Attitude towards Concordance II Scale (LATCon II). J. Teach. Learn. Resources, 9588(1-5). https://doi.org/10.15766/mep_2374-8265.9588

Zainal, N.Z., Nor, A.Y, Subramaniam, P. (2015). Psychometric Properties of the Malay-translated Mindfulness, Attention and Awareness Scale (MAAS) in a Malaysian population. Malaysian J Psychiatry, 24(1), 33-41. https://www.mjpsychiatry.org/index.php/mjp/article/view/352/253

Zainudin, S.P., Mohd, K.M.A., Mohamad, R.N.N. (2020) Mitigation Measures during Elections and It's Impacts on COVID-19 Pandemic: Sabah State (Malaysia), New Zealand and the United States. Borneo Epidemiol J., 1(2), 145-156. https://jurcon.ums.edu.my/ojums/index.php/bej/article/view/2748/1800 